\title{
Metallographic Methods for Troubleshooting of Roll Problems in the Finishing Train of a Ferrous Hot Strip Mill
}

\author{
Ron Webber*, Marian Lalik* \\ *Dofasco Inc., 1330 Burlington St East, Hamilton, Ontario, Canada, L8N 3J5
}

Rolls are a critical tool in the production of flat rolled steel. Being the only solid material that comes in contact with the product, they are essential to ensuring that the required product characteristics of dimension, flatness, profile and surface quality are achieved. In the last 10 years, revolutionary improvements in roll metallurgy have changed the status of the roll from a standard consumable to a technological tool. The drastic improvement in roll performance has also meant an increase in the price of advanced roll types. A better understanding by the user of the relationship between roll metallurgy, microstructure and roll performance is required.

In 1993, Dofasco was one of the first Companies to start using High Speed Steel (HSS) work rolls in the Finishing Stands of the Hot Mill. The initial attempt to relate microstructure to performance used standard metallographic techniques. Samples of the rolls were obtained by lathe cutting. The samples were mounted, polished, etched with 5\% Nital (if required) and observed by either a Scanning Electron Microscope or optical microscopes. Other samples came from rolls that had catastrophically failed, a not too uncommon event in the early days of development. This old technique resulted in several key discoveries.

The superior performance of the HSS is in part due to the replacement of networked chromium carbides found in high chrome rolls with intergranular $\mathrm{MC}$ carbides and $\mathrm{M} 2 \mathrm{C}$ carbides (Figure 1a and $b$ ). It was determined that too high a volume of $\mathrm{M}_{2} \mathrm{C}$ carbides resulted in an unfavourable structure. The brittle carbides created a pathway for cracks to propagate (Figure 2). The cracks would find their way back to the surface and cause a small spall that would lead to quality problems.

Typically, HSS rolls have a higher coefficient of friction than high chrome rolls. Using an SEM, it was shown that the matrix of the roll wears away preferentially and leaves the harder carbides protruding (Figure 3). The effect is much like the steel studs that were used on snow tires to improve traction.

Metallography was also used to confirm that thermal cracks are perpendicular to the roll surface and do not propagate after the initial creation. Mechanical cracks are not normal to the surface and will propagate until the roll fails.

For analysis of in-plant problems, another old technique is being employed. Using acetone tape, replicas can be obtained from rolls that are in service. The replica can be viewed under an optical microscope or, after coating with aluminum, observed with an SEM. This technique has resolved numerous problems and helped in the development of roll technology. A number of examples will be given of rolling problems that were swiftly and cheaply resolved. 


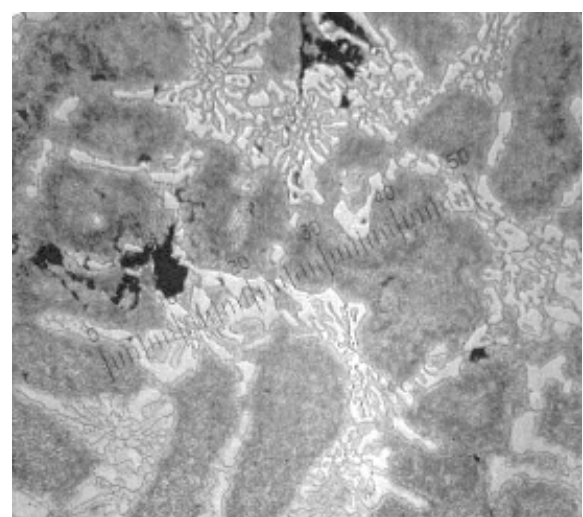

(a)

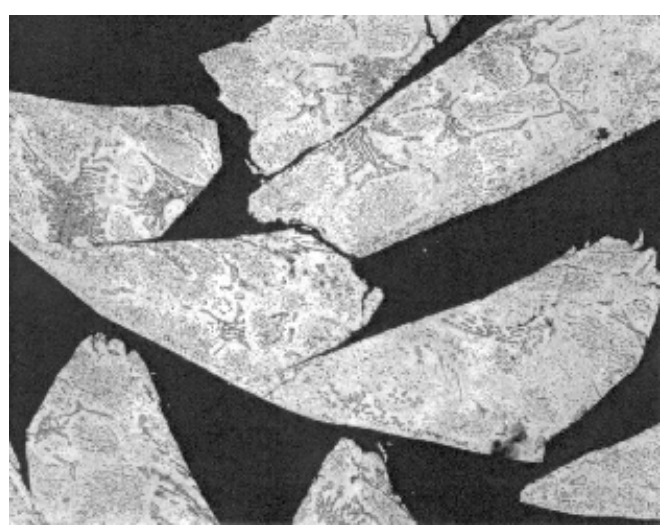

(b)

FIG. 1a. Microstructure of high chrome iron work roll(200 mag).

FIG. 1b. Microstructure of an HSS work roll (200 mag).

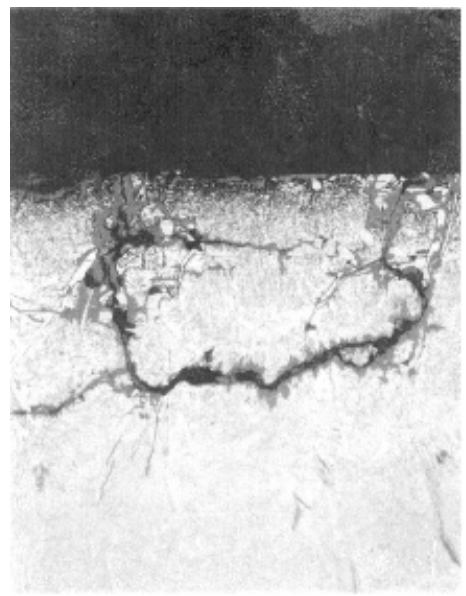

FIG 2. Microstructure of a crack following $\mathrm{M}_{2} \mathrm{C}$ carbides (500 mag).

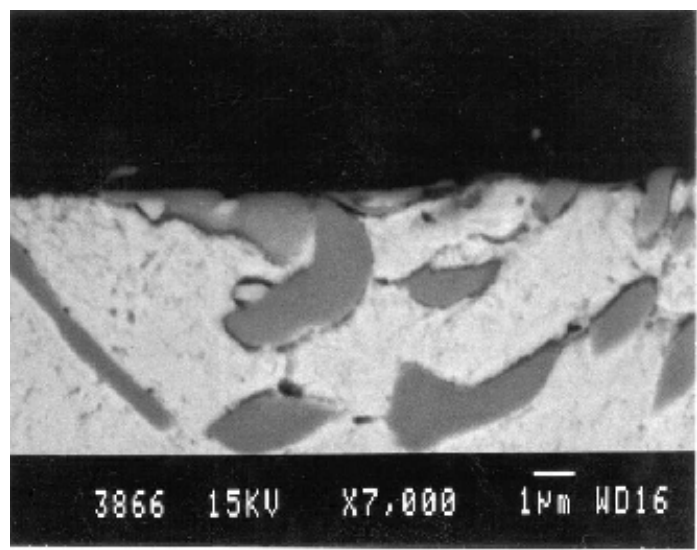

FIG. 3. SEM metallograph of hard carbides protruding from the HSS roll surface. 